\title{
Research on the Effects of Ideological and Political Education in Colleges in the Era of Big Data
}

\author{
Xu Ping \\ Wuhan Business University, Wuhan, 430056, China \\ E-mail:1044796243@qq.com
}

Keywords: Big data; Ideological and political education in universities; Effects

\begin{abstract}
Through reference reading and comparative analysis, this paper conducts a research on the effects of ideological and political education of college students in the era of big data. Firstly, it introduces the basic concept of such education; Secondly, it reveals the incoming opportunities and challenges towards such education by analyzing features of the era. Finally, based on these features, it puts forward corresponding methods. In the era of big data, new ways can be used to receive information and combine advanced IT with online resources. Also, a new model of education can be created by establishing a platform of data technology and MOOCs (Massive Open Online Course) and a strong pipeline of talent can be built so as to make such education more effective.
\end{abstract}

\section{Introduction}

With the rapid development of data technology, data, as a means to analyze problems, is essential. [1] It helps a lot in people's life and work in this century. As a major frontier for knowledge innovation, universities should work hard to integrate and apply relevant technologies of big data. [2] When dealing with students of great creativity and energy, political educators should look forward and take advantages of the opportunities presented by big data technologies to make innovations in respects concerning the subjects, objects and effects of education. However, as everything is both complex and contradictory, new challenges and difficulties will also appear in these respects. [3] For that reason, political educators need to press ahead and work energetically so as to become pioneers in their field in big data era.

\section{New opportunities and challenges brought in the era of big data}

\subsection{Opportunities}

Big data can provide valuable information for political workers. In big data era, we can digitize and store everything including records on daily commuting, real-time communication and even Wechat message.[4] Undoubtedly, it is a good thing for political teachers in universities as they can have access to much information via QQ, Wechat and Mircoblog in ways to know the latest mental conditions of their students.[5] By collecting and analyzing these data, they can not only maximize the data on political education but also improve the past situation when students were not willing or not dare to communicate with their teachers or counselors.

Similarly, big data can offer abundant resources for political education in universities. [6] With the fast development of network, Internet data has been increasing at a dramatic rate. These data provide rich resources for universities. Firstly, in big data era, data is so tremendous that it reverses the data thinking based on paper publications in the age of traditional media. Secondly, there are rich forms of data. [7] Network data include both information of traditional paper media and online information including video, image and web texts, especially those information created by netizens. These various data can enrich the education both in content and form.

\subsection{Challenges}

False data may lead to mistakes in decision-making. Big data era brings opportunities for our 
political education on cyberspace. However, we have to stay calm and alert either conceptually or operationally. We cannot take big data as the only solution to the problems arising from political education but treat it rationally and objectively when using data and exploiting its value. As for such education in universities, we analyze and predict the cognition of subjects and objects through big data technologies and then evaluate its performance from a particular perspective. In that process, we can merely use the analysis of big data for reference.

Complex information in big data causes a confusion of values among college students. Firstly, the western values have a strong impact on them. Due to the differences in economic and social development, western countries have a leading edge in spreading online information. Europe and America use online data to advocate their values worldwide, spreading correct values and political belief among students. Secondly, much bad information confuses the values of students. They may be baffled by those information that seems to advocate freedom and democracy and don't know what correct values are all about as there are much information of different appeals and values.

\section{Building a new pattern of ideological and political education for college students}

The big data era has a profound impact on the political education of college students. Except for the content of data and use of relevant technologies, universities must reform the traditional pattern of education to adapt to changes in the new era.

\subsection{Building a platform of data technology}

To build that pattern, we must have a technical platform for data analysis, which is also a must for universities. One feature of big data and network is to integrate much information into the same platform. When building such platform, universities should not be confined to the storage and analysis of data on students, but make full use of the data concerning enterprises, institutions and social organizations and expand more channels for the collection of valid data. As for the establishment of internal platforms, universities should try to integrate all platforms and give unified management on platforms involving school educational administration, library technology, student life technology management and academic management through cloud technology. Then they can analyze these data through a cloud-computing platform and discover the law of student behaviors.

\subsection{Building a new mode of MOOCs}

In recent days, colleges, at home and abroad, attempt to carry on online courses, namely MOOCs, a platform of big data. It comes from the integration of traditional courses and IT. Combining the analysis of such education in big data era, the author tries to design a new mode of MOOCs. See figure 1 for more details.

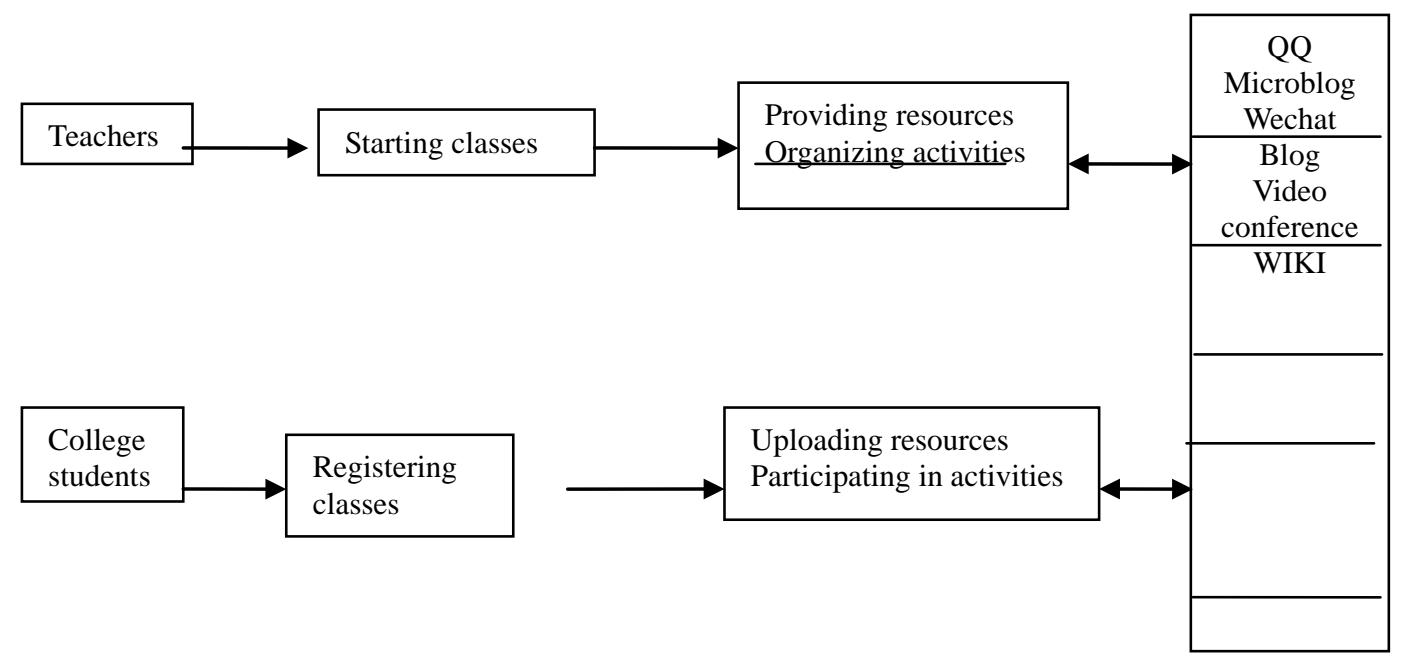

Figure 1 MOOCs on the political education of college students 
Communications are made possible between teachers and students through big data. Meanwhile, the forms supported by information are kept and become part of the materials of big data. College students can also use internet medium to deliver information to their teachers and participate in activities launched by their teachers. By doing so, the two subjects in political education shorten their distance and realize the exchange of equal information.

\subsection{Building a strong pipeline of talent}

Building a strong pipeline of talent is essential for the innovation of educational mode. The biggest difference between data talents and political educators is that, the former master rich political knowledge and teaching experience and has a good understanding of technology application. Our universities have a big talent pool of IT, but fail to turn those talents into persons with much experience in management. In this way, there is a shortage of such talents. That means we should both attract talents and give special training to existing personnel in ways that build a pipeline of talents equipped with basic theories as well as data thinking and analytical ability. Some senior college teachers know little about IT, not to say the big data. Given that, universities can offer professional training to them and build partnerships with companies with a strong capability of data analysis through social human resources. Following the philosophy of service outsourcing, colleges can also outsource part of their special technologies so as to make universities more cost-effective and efficient and political teachers there less resistant.

\section{Conclusions}

As an emerging data reform, big data offers us new ways and perspectives to know the world, especially digital methods for political workers to know what their students are thinking about, thus triggering the reform of traditional education. By using such methods, we can predict the mind and behaviors of students so as to push forward innovations in political education. In big data era, political workers must have a good understanding of new opportunities brought by big data, continuously improve data thinking and ability and overcome challenges in all respects. That is how we can enhance political education effectively and scientifically and foster innovations in the education.

\section{Acknowledgements}

In this paper, the research was sponsored by Wuhan Business University, and the Project Name is Research on the Effects of Ideological and Political Education in Colleges in the Era of Big Data (Project No.2016KZ006).

\section{References}

[1] Massive Open and Online Courses9MOOCin an International Perspective: New Global Agenda for Innovation in Higher Education. Garter Titlestad. 2014

[2] The One World Schoolhouse: Education Reimagined. Salman Khan. 2014

[3] Designing a Course for Stimulating Entrepreneurship in Higher Education through Serious Games[J] . F. Bellotti, R. Berta, A. De Gloria, E. Lavagnino, F. Dagnino, M. Ott, M. Romero, M. Usart, I.S. Mayer. Procedia Computer Science. 2012

[4] An empirical analysis of the adoption of m-learning in Malaysia. Chong, Joan-Lynn, Chong, Alain [5] Yee-Loong, Ooi, Keng-Boon, Lin, Binshan. International Journal of Mobile Communications. 2011 Using'’Microlectures'” to Improve Your Online Courses. Kelly, Rob. Online classroom. 2010

[6] A Comparison of Presentation Methods for Reading on Mobile Phones. Hedin, Bj??rn, Lindgren, Erik. Distributed Systems Online, IEEE. 2007

[7] Ethics Media Communications: cases and controversies. Louis Alvin Day. 2004 